Review Article

\title{
The Involvement of MicroRNAs in Modulation of Innate and Adaptive Immunity in Systemic Lupus Erythematosus and Lupus Nephritis
}

\author{
Mohsen Honarpisheh $\mathbb{D}^{1}{ }^{1}$ Paulina Köhler, ${ }^{1}$ Ekaterina von Rauchhaupt, ${ }^{1}$ and Maciej Lech $\mathbb{D}^{1,2}$ \\ ${ }^{1}$ Department of Nephrology, Medizinische Klinik und Poliklinik IV, Klinikum der Ludwig-Maximilians-Universität München, \\ Munich, Germany \\ ${ }^{2}$ Department of Microbiology, Faculty of Biochemistry, Biophysics and Biotechnology, Jagiellonian University, Krakow, Poland
}

Correspondence should be addressed to Maciej Lech; maciej.lech@med.uni-muenchen.de

Received 28 September 2017; Accepted 3 April 2018; Published 8 May 2018

Academic Editor: Baohui Xu

Copyright (C) 2018 Mohsen Honarpisheh et al. This is an open access article distributed under the Creative Commons Attribution License, which permits unrestricted use, distribution, and reproduction in any medium, provided the original work is properly cited.

\begin{abstract}
Noncoding RNAs (ncRNAs), including microRNAs (miRNAs), represent a family of RNA molecules that do not translate into protein. Nevertheless, they have the ability to regulate gene expression and play an essential role in immune cell differentiation and function. MicroRNAs were found to be differentially expressed in various tissues, and changes in their expression have been associated with several pathological processes. Yet, their roles in systemic lupus erythematosus (SLE) and lupus nephritis (LN) remain to be elucidated. Both SLE and LN are characterized by a complex dysfunction of the innate and adaptive immunity. Recently, significant findings have been made in understanding SLE through the use of genetic variant identification and expression pattern analysis and mouse models, as well as epigenetic analyses. Abnormalities in immune cell responses, cytokine and chemokine production, cell activation, and apoptosis have been linked to a unique expression pattern of a number of miRNAs that have been implicated in the immune pathogenesis of this autoimmune disease. The recent evidence that significantly increased the understanding of the pathogenesis of SLE drives a renewed interest in efficient therapy targets. This review aims at providing an overview of the current state of research on the expression and role of miRNAs in the immune pathogenesis of SLE and LN.
\end{abstract}

\section{Pathogenesis of Systemic Lupus Erythematosus}

Systemic lupus erythematosus (SLE) is a chronic autoimmune disease characterized by a loss of tolerance against nuclear autoantigens, lymphoproliferation, polyclonal autoantibody production, immune complex deposition, and tissue inflammation [1]. SLE used to be referred to as a complex autoimmune disease of unknown etiology; however, during the last decade, a multidisciplinary approach to SLE-relevant research has built a more concise view of the pathogenesis of the disease. SLE develops from a loss of self-tolerance to ubiquitous autoantigens, which can be seen as a result of a failed immunization process. This observation implies two assumptions. First, autoreactive, long-lived plasma cells and memory $\mathrm{T}$ cells memorize their immunization against autoantigens. Second, the autoantigens must be accessible to antigen-presenting cells (APCs), a process that is normally avoided by various homeostatic mechanisms. In fact, SLE develops in individuals with unfortunate combinations of genetic variants that, among other immunoregulatory defects, compromise those mechanisms that normally assure low levels of autoantigens in extracellular compartments (Figure 1). Overshooting activation of antigen-presenting cells (APCs) turns the interpretation of autoantigens from immune ignorance and lymphocyte anergy into lymphocyte activation and proliferation, which can overcome the functional unresponsiveness or anergy of mature autoreactive B cells [2]. The "danger" hypothesis model postulates that one of the sources of inflammation that 


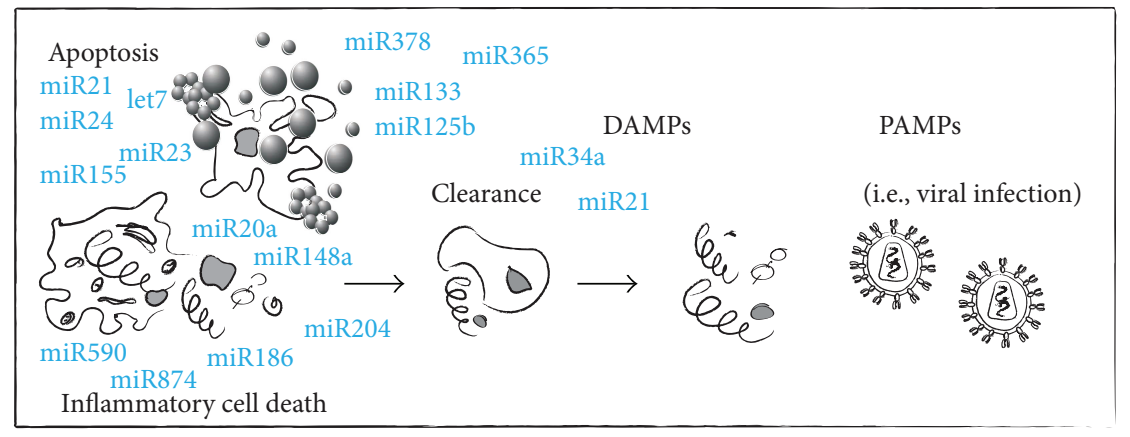

Inflammatory cell death
Genes and proteins involved in SLE:

C1q, C2, C4A/B, DNAse1 CRP, ATG5, TREX1, Bcl-2,

Bim, Il-2, IL-2R $\beta$, CRP

MicroRNA involved in SLE:

miR155, miR146a, miR31, miR17, miR148a, miR152, miR18a, miR19a, miR20a, miR29b, miR29c, miR181a

Genes and proteins involved in SLE:

FcGR2A/3A/3B, HLA-B8/DR2/DR3 IRAK-1, IRF-5, STAT-4, ITGAM, TNFAIP3, LYN, Ly9, TLR7, SLAM, PTPN22, BAFF, IRF1/3/4/5/7/8,

IL-1/2/4/6/10/15/18/21/27,

IFN-gamma, type I IFNs, IFIHI, IRAK-1, CD40, CD44

MicroRNA involved in SLE:

let7a, miR30a, miR146a, miR3148, miR155, miR21, miR142, miR125b, miR31, miR1246, miR22, miR125a, miR410

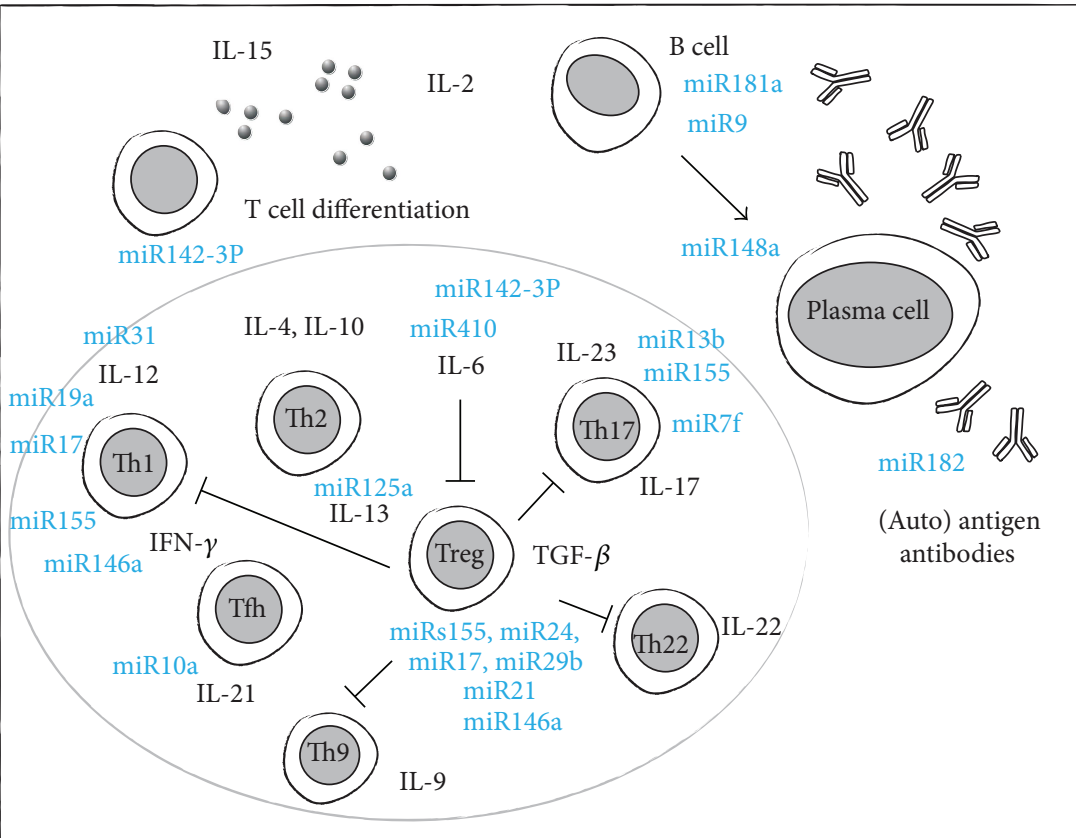

Genes and proteins involved in SLE:

BANK1, BLK, ETS1, IKZF1, LYN,

ATG5, STAT-1, STAT-4,

PTPN22, PTTG1, RASGRP3,

TNFSF4, TNIP1, TRAF3IP2, HCP5, PDCD1, SPP1, MECP2, PXK, ICA1, IRF1/3/4/5/7/8, IFN- $\gamma$, CD40, CD44 IL-1/2/4/6/10/15/17/18/21/27, CD22

MicroRNA involved in SLE:

miR146a, miR125b, let7a, miR30a, miR1246, miR145, miR150, miR22, miR125a, miR410, miR31, miR142, miR21, miR23b, miR148a

Figure 1: Pathogenesis of systemic lupus erythematosus. 
may lead to autoimmunity is the generation of alarm signals by injured cells [3]. The injury that results from pathogens, toxicants, or trauma can trigger the release of the so-called damage-associated molecular pattern (DAMP). However, cells dying by any programmed and controlled cell death do not activate APCs. The distinct responsiveness to foreign-but-harmless (i.e., fetuses) and self-but-harmful (i.e., certain mutations) materials needs to be extensively studied in order to understand the development of autoinflammatory and autoimmune diseases.

Multiple genetic and environmental factors are at play during the development of SLE [4]. A few events including a general tolerance break within adaptive immunity and the overall innate immune system as well as local processes and susceptibility factors within the organs seem to be crucial for progression of SLE $[5,6]$. The hallmark of SLE is the presence of autoantibodies directed against nuclear antigens, which result in autoantibody-mediated end-organ damage [5]. Numerous experimental studies show that various mice strains exhibit a lack of immune tolerance to nuclear antigens, resulting B cell hyperactivity and elevated number of $B$ cell subsets in the production of autoantibodies $[7,8]$. Moreover, scientists observed increased number of autoreactive $\mathrm{T}$ cells with increased expression of activation markers on these cells $[9,10]$. One of the important checkpoints is the immune tolerance maintained by the adaptive immunity, controlling autoreactive B cells and T cells [11]. The autoreactive cells are removed in the bone marrow (BM) and thymus, respectively. In the thymus, the $\mathrm{T}$ cells undergo negative selection to avoid the spreading of cells that recognize self-antigens and to promote cells that tolerate one's own tissues. This process use antigen-presenting cells (APCs) that present self-antigens to early-stage $T$ cells [12]. There should be no doubt that $\mathrm{B}$ cells play a crucial role in autoimmune reactions and their depletion may represent an effective treatment of autoantibody-driven injuries [12]. Indeed, it is not surprising that the number, activity, and elimination of autoreactive $\mathrm{B}$ cells in the bone marrow (BM) or in peripheral lymphoid tissues can orchestrate the progression of SLE $[13,14]$. Another checkpoint consists of a universal form of host defense referred as the innate immunity $[15,16]$. These mechanisms are important in maintaining acute inflammatory responses to pathogenic and environmental stimuli such as viruses or sterile inflammation. When this checkpoint fails to function properly, peripheral autoinflammatory responses may arise and consequently lead to development of autoantibodies [17]. On the cellular level, especially peripheral inflammation orchestrating myeloid cells and interferonproducing pDCs were linked to SLE-phenotype and have a strong impact on lupus pathogenesis [18]. Lack of homeostasis within innate immune responses, chronic ongoing inflammation, and impaired clearance of dead cells may initiate the severe tissue damage [19]. The consequence of dysregulation within these innate and adaptive immunity checkpoints is the presence of autoantibodies, followed by immune complexes, accumulation of $\mathrm{T}$ cells and myeloid cells, and rising proinflammatory conditions. Moreover, many other processes such as cell death, the clearance of dead cells, antigen presentation, and adhesion of infiltrating cells may determine susceptibility to tissue- or organ-specific manifestation of lupus [18, 20-22].

\section{Cells and Mechanisms Involved in the Development of SLE}

B cells are well-studied participants in the development of SLE as well as other autoimmune diseases [23-25]. B lymphocyte stimulators such as $B$ cell-activating factor (BAFF) and a proliferation-inducing ligand (APRIL) regulate $B$ cell differentiation and Ig class switching [26] and promote plasma cell survival [27]. Until now, they were predominantly considered as potential therapeutic targets in SLE because the presence of autoantibodies is a hallmark feature of many autoimmune diseases and autoantibody production was thought to be the one and only role of B cells in SLE. Among the autoantibodies found in SLE patients, some such as anti-dsDNA and anti-Sm antibodies display particular clinical and diagnostic importance and are highly specific for SLE. Indeed, elimination of autoantibodies was unsuccessful in a controlled clinical trial [28], and treatment of some SLE patients with rituximab in order to deplete B cells resulted in clinical improvement without affecting antidsDNA antibody levels [29]. Moreover, experimental studies proved that antibody-deficient mice still develop the SLE-like disease and LN [23]. This fact may support another hypothesis that, except B cells, other cells and local proinflammatory effects are involved in the development of the disease. Indeed, various studies have shown that without the assistance of the helper $\mathrm{T}$ lymphocytes, it is difficult for the $\mathrm{B}$ cells alone to trigger SLE pathogenicity. T cells possess the potential to become key players in the development and progression of SLE. Their capabilities to communicate with other cells of the immune system are unique and need to be tightly regulated. Interestingly, in comparison with healthy individuals, various studies have shown that $\mathrm{T}$ cells isolated from patients with SLE are abnormal, regarding both their phenotypes and functions [30, 31]. Studies showed that the expansion of the Th17 population and the downstream signaling of $\mathrm{T}$ cell receptors (TCRs), as well as epigenetics, differs in SLE patients compared to healthy individuals. Additionally, the function and number of regulatory $\mathrm{T}$ lymphocytes were distinct in SLE patients and healthy subjects [32-34] and immunosuppressive therapies restored the number of functional Tregs in patients with SLE [35-37]. In addition, high expression of CD40L detected on lupus T cells was responsible for excessive stimulation of CD40 expressed on B cells. CD40 signaling triggers the production of autoantibodies, which supports the hypothesis that SLE is a T cell-related disease. Also, innate immunity responses represented by dendritic cells and macrophages play an important role in the development of SLE. Antigen-presenting cells (APCs) are essential in establishing and maintaining peripheral tolerance as well as in the regulation of immune responses. This is accomplished via diverse regulatory mechanisms that regulate inflammation. Furthermore, they are responsible for the clearance of dying cells. An increased level of apoptotic material was associated with the incidence of SLE and the disease severity [38]. Several antigens released from the dying cells can result from 
increased cell death and/or insufficient clearance of dying cells. APCs are distributed in the tissues for optimal antigen capture. They have the capacity to process antigens and present antigens to T cells. This process results in anergy or elimination of self-reactive $\mathrm{T}$ cells and the development of regulatory T cells [39]. Apart from the functions mentioned above, it is possible that overshooting immune responses of classically activated inflammatory macrophage responses induce the imbalanced macrophage signaling and lead to the runaway inflammation that is one of the crucial features of SLE [40]. Dendritic cells which are widely represented throughout all the tissues play likewise an important role in SLE. Experimental studies in mice show that the depletion of DCs in mice leads to a CD4 T cell-dependent selftolerance break and induces autoimmunity [41]. It is important to mention that especially particular types of DCs such as myeloid DCs (mDCs), regulatory DCs (rDCs), and plasmacytoid DCs (pDCs) are involved in the development of the disease [42-44]. pDCs that can be isolated from blood or generated in vitro from human monocytes or mouse bone marrow stimulated with Flt-3 ligand (Flt-3L). In contrast to $\mathrm{mDCs}, \mathrm{pDCs}$ do ingest apoptotic and necrotic material only in form of immune complexes and produce large amounts of type I IFN which is involved in the pathogenesis of SLE $[42,45,46]$.

One of the challenges in immunology over the past decades has been to unravel the mechanisms of immunological tolerance. The tolerance checkpoints control lymphocyte responses, their selection, activation, and neutralization. All these features are necessary to enable proper immune responses and to avoid autoimmunity. Recently, epigenetic modulations executed by microRNAs (miRNAs), that introduce the changes in gene expression, move the importance of regulatory processes to the fore. They allow regulation of immunological functions of cell subsets orchestrating innate immune responses and $\mathrm{T}$ cells as well as B cell and plasma cell differentiation [47]. Consequently, miRNAs may play an important role in altering inflammation and development of autoimmune disorders. Changes in miRNA expression and miRNA-mediated regulation of autoimmune genes may be a reason for susceptibility to complex autoimmune diseases such as SLE. MicroRNA-mediated inhibition of gene expression has not without a reason gained importance in both regulating autoimmune-relevant responses and modulating inflammatory responses (Figure 1). miRs have the unique capacity to repress the expression of target transcripts rapidly and precisely to prevent the development of antiinflammatory responses and balance between effective host defense and autoimmunity.

\section{Biogenesis of MicroRNA}

Mature microRNAs are usually 19-22 nucleotides in length and regulate gene expression in posttranscriptional level. Their binding sites are normally located in $3^{\prime}$ untranslated region (UTR) of target mRNA. The genes encoding the primary transcripts (pri-miRNA) of microRNA can be found in intergenic regions of the genome or within introns of protein-coding genes. First, pri-miRNA is produced by
RNA polymerase II and III in the form of long transcripts containing hairpin stem-loop structure [48-50]. Secondly, the maturation process of pri-miRNA is mediated by nuclear RNase III Drosha and its cofactor DGCR 8 (DiGeorge syndrome chromosomal region 8) [51]. They form so-called microprocessor complex [52] that releases 65-70-nucleotide-long small hairpin precursor microRNA (pre-miRNA) from stem-loop structure [53]. Followed by processing of pre-miRNA by Drosha, pre-miRNA is exported into the cytoplasm by mediating of Exportin 5 (EXP5) protein and a cofactor called Ran-GTP [54-56]. In addition, it was reported that downregulation of EXP5 reduces the translocation of pre-miRNA into cytoplasm but does not enhance accumulation of the pre-miRNA in the nucleus. This finding suggests that the EXP5 protects the microRNA from exonucleolytic digestion in the nucleus [55]. In the cytoplasm, other enzyme called Dicer cleaves the pre-miRNA and produces a small double-strand RNA (dsRNA) [57, 58]. Subsequently, dsRNA is loaded onto Argonaut (Ago) protein to form RNA-induced silencing complex (RISC) $[59,60]$ in order to unwind the dsRNA and produce mature guide strand [61]. There are eight Ago proteins identified in human [62] but only four [1-4] are able to load miRNA or siRNA regardless of their structure $[63,64]$. miR-RISC complex is an effector that mediates silencing process [65]. Within this complex, the seed region of miRNA (2-8 nucleotides) is a most critical region for selecting the mRNA targets [66]. In this form, microRNAs have the ability to mediate pretranslational, cotranslational, or posttranslational silencing [67]. Apart from the canonical pathway of miRNA processing, the noncanonical (microprocessor- or Dicer-independent) pathway have been described [68-71]. This alternative mechanism was first seen in mitronprocessing pathway $[72,73]$ where pre-RNA is produced by mRNA splicing and is independent of Drosha [70,71]. Some small RNAs may also originate from other noncoding RNAs such as small nuclear RNAs [74], tRNAs [70], and small viral RNAs [75]. The biogenesis of these RNAs is also independent of Drosha but still dependent on Dicer.

\section{MicroRNA in SLE and LN}

MicroRNA expression patterns in lupus-prone mice and lupus patients indicate the clinical relevance of miRNAs in SLE $[76,77]$. In addition, anti-Su autoantibodies, which can be detected in SLE patients, were shown to bind to the critical catalytic enzyme in miRNA pathways (Argonaute 1-4 and Dicer) [78, 79]. A direct link between SLE and miRNA expression was first investigated by Dai et al. who identified different expression patterns in a few miRNAs in peripheral blood mononuclear cells (PBMCs) from SLE patients compared to healthy controls [76]. In the last years, it has been clearly recognized that SLE patients display distinct expression patterns of miRNAs including circulating miRs, which need to be correlated with the aspects of the disease development and progression [80-87]. Some microRNAs such as miR-371-5p, miR-423-5p, miR-638, miR-1224-3p, and miR-663 were found to be conserved and clearly regulated in the PBMCs of lupus nephritis patients across patient 
groups of different races [87]. Another comprehensive study of human lupus nephritis identified 66 miRs that were differentially expressed between patients with lupus nephritis and healthy controls [88]. Also, more precise correlations were performed recently. Vinuesa et al. computationally analyzed 72 lupus susceptibility genes and showed that most genes involved in the pathogenesis of the disease contain potential multiple target sites for over 140 conserved in mammal's microRNAs [89]. Three miRNAs (miR-181, miR-186, and miR-590-3p) are predicted to target over $50 \%$ of all lupus susceptibility genes. Some of the miRs such as miR-181, miR186 , and miR-590-3 are believed to be strongly associated with the predisposition to the disease [89]. The same study predicted single miR-495, which belongs to the miR-329 gene cluster comprised of 11 miRNAs (miR-134, miR-154, miR299, miR-329, miR-376, miR-376c, miR-494, miR-495, miR-543, and miR-758) to regulate multiple lupus genes. Moreover, microRNAs such as miR-216, miR-411, miR296-3p, and miR-361 5p targeted more than $10 \%$ of SLE genes [89]. In another cohort of patients, Stagakis et al. identified 27 dysregulated miRNAs in the PBMCs of SLE patients, 2 of which were consistent with miRNAs identified by Dai et al. and 19 of which correlated with disease activity $[76,90]$. Eight of the latter appeared to be differentially expressed in T cells and four of them were deregulated in B cells. Another study showed that 7 abnormally expressed miRNAs (miR-145, miR-224, miR-150, miR-483-5p, miR513-5p, miR-516a-5p, and miR-629) are present in SLE T cells compared to healthy controls [91]. Hyperactive T cells from patients seem to display distinct microRNA signature than $\mathrm{T}$ cells from healthy patients $[90,92,93]$. All these findings are well-recognized pieces of evidence of miRNAmediated pathogenesis of SLE. However, the extensive analysis of the expression levels of microRNAs in SLE patients in comparison with healthy individuals did not necessarily reveal any pattern of dysregulated microRNA. The variations observed within populations which were investigated as well as different detection methods disable a specific comparison between the results from single studies. This may explain why some investigations showed less cohesive microRNA expression results. Serum level of miR-223 in SLE patients from different ethnic groups was shown increased in PBMCs from Chinese SLE patients [94] and significantly downregulated in European patients with active lupus nephritis [83].

Apart from correlations and computational analysis, the role of miRNAs in the development of autoimmune diseases has been demonstrated in various experimental studies. Deletion of Drosha or Dicer in T cells evidenced the important function of miRNA in T lymphocytes [95-97]. The absence of miRs was associated with decreased $\mathrm{T}$ cell number and increased inflammation. This phenomenon could be explained by deregulated Tregs suppressive phenotype. For instance, Dicer deficiency in Treg cells leads to the development of systemic autoimmune diseases [98, 99]. SLE-prone MRL/lpr lupus was shown to display reduced Treg-maintained suppressive activity due to spontaneous Dicer insufficiency in these cells [100]. Moreover, the experimental studies with B cell-specific knockouts of Dicer have shown that microRNAs not only play a role in B cell- maintained immunity but also are involved in the development of autoimmune responses as well [101-104].

Various experimental studies reveal that microRNAs are differentially expressed in male and female $[105,106]$. This information seems to be relevant since females have higher incidence of SLE as compared to male. Furthermore, epidemiological and clinical data demonstrate that unlike males, the females tend to develop severe disease [107]. This sexdifferential susceptibility to SLE may be influenced by genes expressed on sex chromosomes and the level of sex hormones [108-110]. Several microRNAs have already been described to be affected by the estrogen levels [111-113]. Moreover, the administration of the primary female sex hormone estrogen to males that underwent orchiectomy affects the expression of lupus-relevant microRNAs [114]. The susceptibility to SLE observed in female may be supported by the positive correlation of estrogen levels with manifestation of the disease. However, since estrogen regulates the inflammatory cytokines and interferon as well as the activation of B cells, its exact direct or indirect effects on microRNAs and autoimmunity remain elusive [115-117]. Moreover, variable expression of some genes in females is influenced by the process of $\mathrm{X}$-chromosome inactivation (XCI). The extra X chromosome in females undergoes this process during embryogenesis. However, over $15 \%$ of human X-linked genes remain to be expressed from the inactive $\mathrm{X}$ chromosome [118]. The impact of such escape genes in sexually dimorphic disease risk may display significant effects on immune responses [119]. For instance, the expression of TLR7 and CD40LG that are located on $\mathrm{X}$-chromosome was reported to be increased in SLE patients $[120,121]$. On a cellular level, these sex-based differences are evidenced in pDC signaling. Laffont et al. showed that pDCs from women display enhanced TLR7-mediated IFN- $\alpha$ production as compared with same cells isolated from males. The authors linked these findings to both estrogen levels that promote innate functions of pDCs and human X-linked genes [122].

\section{MicroRNA Regulating Innate Immune Responses Involved in Development of SLE}

It is not surprising that various SLE-relevant processes such as proinflammatory cytokine production, cell death, and antigen presentation can be affected by microRNAs. However, many of the microRNAs that were found showed different expression pattern between lupus patients and healthy controls in peripheral blood mononuclear cells (PBMCs) may be involved in regulation of interferon (IFN) type I pathway $[87,123]$. For instance, the expression of miR-146a was shown to correlate with the SLE disease activity and IFN signaling by targeting IRF5 and STAT1 which were both described as important genetic factors in the development of SLE [123]. In addition, changes in miR-146a expression were associated with dysregulated IFN responses. Regulation of transcription factors IRF5 and STAT1 by this microRNA was confirmed. Furthermore, miR-146a was shown to downregulate TRAF6-, IRAK1-, and IRAK2-mediated inflammatory signals in macrophages and affects the type I IFN production in these cells [124]. Among all dendritic cells, 
pDCs were described to play a crucial role in SLE development due to their ability to secrete a significant amount of type I IFN upon TLR7/9 stimulation [125]. Consequently, in plasmacytoid dendritic cells (pDCs), upregulated levels of microRNA-146a were shown upon TLR7/9 stimulation. Moreover, this microRNA plays a role in pDC survival [126]. These recent studies could indeed evidence miR-146a as a key regulator of pDC function. This hypothesis was already supported by the study showing that overexpression of miR-146a in the CAL-1 pDC cell line triggers apoptosis, impaired TLR7-dependent inflammatory processes, and decreased the ability of pDCs to drive CD4+ T cells proliferation [126]. In addition, a recent study identified a new key player in pDC signaling. It reported that type I IFN inhibits the maturation of miR-146a through the upregulation of MCPIP-1 and that this phenomenon contributes to the uncontrolled inflammation and excessive inflammatory gene expression in SLE [127]. In silico investigations suggested further potential microRNAs that might target the INF pathway. Notably, some of these microRNAs appeared to be dysregulated in PBMCs of SLE patients [87].

Another crucial pathway in the development of SLE is NF- $\kappa$ B-related inflammation. Let-7 miRNAs were shown to modulate the activation of NF- $\kappa$ B by targeting another SLErelevant negative regulator of innate responses, namely, TNFAIP3 [128]. Overexpression of Let-7 miRNAs led to increased TNF $\alpha$ stimulation and production of cytokines in HEK293T cells. In addition, the expression of Let-7 miRNAs was significantly upregulated, and the TNFAIP3 level was remarkably downregulated in samples from LN patients compared to control samples suggesting another potential target for therapeutic intervention [128]. Recently, Wang et al. identified miR-663a/miR-423-5p as microRNA modulating the activation of NF- $\kappa \mathrm{B}$ by binding to TNIP2. This novel $\mathrm{miR}$ was suggested to be involved in the pathogenesis of lupus nephritis [129]. Levels of miR-663a/miR-423-5p were high in kidney tissues from LN patients as compared to kidney tissues from SLE patients without significant renal phenotype and normal tissues. Consequently, TNIP2 was downregulated in tissues from LN patients. Consistent with the data, an experimental pristane-induced model of LN was characterized by increased levels of $\mathrm{miR}-663 \mathrm{a} / \mathrm{miR}$ 423-5p and reduction of TNIP2 transcript in response to renal injury. miR-663a/miR-423-5p mimics and inhibitors triggered decrease and increase of TNIP2 levels, which, respectively, might provide new therapeutic targets for $\mathrm{LN}$ treatment [129]. One of the best-characterized miRs involved in both NF- $\kappa \mathrm{B}$ - and IFN-dependent inflammatory and autoimmune conditions is miR-155. It was shown to regulate innate immune response by inhibiting MyD88 and TAB2dependent inflammatory responses $[130,131]$. Interestingly, miR-155 upregulates the type I interferon signaling in macrophages by inhibiting the suppressor of cytokine signaling1 (SOCS-1) [132]. As previously mentioned, the type I IFN is one of the key cytokines promoting the development of SLE. Surprisingly, miR- $155^{*}$ that originates from the same precursor and is also induced by TLR7 through the c-Jun $\mathrm{N}$-terminal kinase pathway had opposite effects on the regulation of type I interferon production of pDC [133]. While early-stage-produced miR-155* increased interferon- $\alpha / \beta$ expression by suppressing IRAKM, late-stage-expressed miR-155 inhibited their expression by targeting TAB2 [133]. This suggests their cooperative involvement in $\mathrm{pDC}$ function and activation. Moreover, miR-155-deficient mice with pristine-induced lupus model displayed significantly lower serum levels of autoantibodies and had less pulmonary involvement and renal disease compared to wild types. These mice showed a less prominent $\mathrm{T}$ cell response and lower expression of genes responsible for disease development, including interferon type I dependent genes [134]. Another study that investigated the potential of miR-155 in SLE showed that miR-155 suppresses autoimmunity through transcriptional repression of PU.1 and TNF- $\alpha$, which in turn suppresses BAFF and CD19 protein expression. miR-155 decreased, therefore, the proportion of BAFF-expressing $\mathrm{B}$ cells and CD19 protein expression [110]. MicroRNA-155 expression was also significantly increased during the development of diffuse alveolar hemorrhage (DAH) which is rare but life-threatening complication of SLE. DAH progression in pristane-induced lupus was reduced in miR-155-deficient mice as well as by in vivo treatment with a miR-155 antagomir [135]. These results suggest that antagonizing miR-155 might be beneficial for SLE patients with complications such as acute lung inflammation. A recent experimental study that also used the model of pristane-induced inflammation identified miR-302d as a key regulator of type I IFN-driven gene expression. miR-302d targets IRF9, regulates interferonstimulated genes (ISG) expression, and protects against autoimmunity in mice [136]. Another IFN regulatory factor-8 (IRF-8), a crucial transcription factor for pDC development and activation, was described as a target of miR-618. Upregulation of miR-618 can inhibit the development of pDCs from CD34+ cells in vitro and interestingly also promote their ability to secrete IFN $\alpha$ [137].

Other miRs were also described to affect innate immune responses by targeting SLE susceptibility genes. miR-3148 regulates expression of TLR7 by binding to its $>3^{\prime}$ UTR [138]. Let-7c downregulates B lymphocyte-induced maturation protein-1 (Blimp1) as well as suppressor of cytokine signaling-1 (SOCS1) expression in dendritic cells, contributing to the extensive production if SLE-relevant proinflammatory cytokines [139].

\section{MicroRNA Regulating Adaptive Immunity Involved in Development of SLE}

Many new studies focus on the miRNA-dependent mechanisms that regulate the signaling and development of $\mathrm{T}$ cells and the imbalance of the T lymphocyte subsets have been implicated in different histological manifestations of SLE. MicroRNAs seem to play an important role in the $\mathrm{T}$ cell-mediated responses. For instance, miR-126 and miR148a are upregulated in T cells isolated from SLE patients and affect the DNA methylation by reducing the expression of DNA methyltransferase 1 (DNMT1) [140-142]. Moreover, high levels of miR-21, miR-148a [141], and miR29b [143] were shown to positively correlate with DNA 
hypomethylation in lupus CD4+ T cells, and suppression of these miRs is beneficial [141, 143]. High expression of miR-21 has been shown to correlate with SLEDAI score [90]. In CD4+ T cells and macrophages, miR-21-dependent suppression of PDCD4 expression affects proliferation, IL10 , and CD40L expression and consequently promotes the development of plasma cells and IgG production [90, 144]. Inhibition of another miR, namely, miR-142-3p/5p in CD4+ $\mathrm{T}$ cells, which was observed also in SLE patients, was associated with increased levels of IL-4, IL-10, CD40L, and ICOS protein expression and could be linked to B cell hyperactivity [145].

There is evidence that apart from interferon type I also some cytokines and chemokines can have an active role in the pathogenesis of SLE and contribute to the immune imbalance in the disease. For instance, downregulation of IL-2 production is one of the features observed in SLE pathogenesis and T cell-dependent production of IL-2 was shown to be impaired in SLE patients [146]. IL-2 plays a dominant role in immune tolerance and inflammatory responses and is important in regulatory $\mathrm{T}$ cell maintenance [147]. The low Il-2 production in T cells was linked to the expression of miR-31 in SLE patients [148]. Further investigations demonstrated that miR-31 negatively regulates FOXP3 expression [149]. A recent study reported that decreased miR-200a-3p causes IL-2 hypoproduction in a lupus-prone mouse and that low levels of miR-200a-3p affect the binding of the ZEB1-CtBP2 complex to the IL-2 promoter and suppress IL-2 production [150].

In the past few years, the classical $\mathrm{T}$ cell paradigm has been expanded to include the proinflammatory Th17 cells, which express of the transcription factor ROR $\gamma \mathrm{t}$ and influence immunosuppressive regulatory $\mathrm{T}$ cells. Interleukin-17 (IL-17) produced by Th17 contributes to inflammatory autoimmune diseases. Zhu et al. showed in their study that miR-23b is downregulated in both inflammatory lesions of humans with lupus and in the mouse models of lupus. The study evidenced that miR-23b suppresses IL-17-, tumor necrosis factor $\alpha$ - (TNF- $\alpha$-) or IL- $1 \beta$-induced NF- $\kappa$ B activation, and inflammatory cytokine expression by targeting TGF- $\beta$-activated kinase $1 /$ MAP3K7 binding protein 2 (TAB2), TAB3, and inhibitor of nuclear factor $\kappa$-B kinase subunit $\alpha(\mathrm{IKK}-\alpha)$ [151]. Recently, miR-873 expression was shown to be significantly upregulated in patients with SLE [152]. Its expression was positively associated with the disease severity. CD4+ T cells, especially the Th17 subset, were found to be the major source of miR-873, and its function was linked to differentiation of CD4+ T cells into the Th17 lineage by downregulating the inhibitor of Th17 cell differentiation in a forkhead box O1- (Foxo1-) dependent manner. Furthermore, in vivo inhibition of miR-873 significantly reduced the disease severity in MRL/lpr mice [152]. Also, miR-30a that is downregulated in human and mouse SLE inhibits IL-17-mediated NF- $\kappa$ B and MAPK activation, leading to a reduced production of inflammatory cytokines and chemokines by targeting Traf3ip 2 mRNA that is coding for Act1 [153].

Studies in SLE patients and murine models have confirmed the importance of Th2 subsets in the pathogenesis of SLE. Indeed, patients with lupus nephritis had significantly lower levels of Th1-cytokines than IL-4 and IL-10, suggesting a clear shift towards the type 2 cytokine phenotype [154]. Moreover, the levels of the type 2 cytokine IL-10 correlated with titers of anti-dsDNA antibodies [155]. miR-410 expression in T cells of SLE patients was decreased compared to that in healthy controls [156]. Its function was associated with the supersession of the STAT3 transcription activity and was accomplished by binding directly to the 3 'UTR of STAT3 mRNA and regulating the expression of IL-10 [156]. Consequently, overexpression of miR-410 significantly reduced the expression levels of IL-10 [156]. Another study identified miR-410 as a factor reducing the expression of interleukin- 6 and as a suppressor of LN-mediated renal fibrosis [157].

A downregulation of another miR, namely, miR-451a reduced the enlargement of the spleen as well as the proteinuria and immune complex deposits in SLE mouse model. The deficiency of miR-451a abated numbers of CD4+CD69+ and CD4+/CD8+ T cells and the levels of the serum cytokines IL-17a and IL-4. The IFN regulatory factor (IRF) 8 was a target of miR-451a in vitro and in vivo [158]. Overexpression of miR-142-3p in monocyte-derived DCs (moDCs) caused an increase of SLE-related cytokines, such as CCL2, CCL5, CXCL8, IL- 6 , and TNF- $\alpha$, and resulted in increased infiltration of CD4+ T cells and in suppression of Tregs in DCCD4(+) T cell coculture, whereas the proliferation of CD4+ $T$ cells was not altered [159]. This strong regulation of the proinflammatory function, as well as the attraction of a significant number of $\mathrm{CD} 4+\mathrm{T}$ cells, was associated with changed expression of miR-142-3p. miR-125a was shown to be substantial for signaling of another decisive $\mathrm{T}$ cell subpopulation. It stabilizes both the commitment and immunoregulatory capacity of Treg cells. In miR-125a-deficient mice, the balance shifts from immune suppression to inflammation. miR-125a suppresses several effector $\mathrm{T}$ cell factors including Stat3, IFNg, and IL-13. Moreover, its chemically synthesized analog had the potential to reprogramme the Treg-mediated immune homeostasis [160]. Some of the miRs targeting innate and adaptive immune responses were included in Table 1.

As already mentioned before, also B cells which are the source for autoantibodies play a central role in disease pathogenesis and progression. SLE patients show abnormal B cell activation and differentiation to memory or plasma effector cells and consequently secretion of autoantibodies that are fundamental in the pathogenesis of local inflammation and organ injury. Diverse profiling studies performed on hematopoietic cell lineage showed the differential regulation of microRNAs in B cells. Notably, miR-16, miR-30c, miR-34a, miR-142-3 and 5p, miR-150, miR-155, miR-181, and miR223 were found to be substantial in B cells [161-164]. Some of these microRNAs such as miR-142-3p and $5 p$ were postulated to be involved in antibody production [145]. Moreover, deep-sequencing study shows the expression of 232 known microRNAs and found B cell stage-specific profiles [165]. The authors confirmed the previous results and investigated the expression profiles of miR-150, miR-146a, miR-155, and miR-181 in detail. Furthermore, they identified and 
TABLE 1: MicroRNAs involved in the pathogenesis of systemic lupus erythematosus.

\begin{tabular}{|c|c|c|c|c|}
\hline Cells & $\operatorname{miR}(s)$ & Target(s) & Function(s) & Ref \\
\hline \multirow{4}{*}{ DCs } & $\operatorname{miR}-126$ & Tsc-1 & Negative regulation of mTOR-miR-126-VEGFR2-axis & [178] \\
\hline & miR-155 & Ship1, KPC1 & Intervenes in CD40 expression & [179] \\
\hline & miR-146a & $\begin{array}{l}\text { STAT1, IRF5, } \\
\text { IRAK1, TRAF6 }\end{array}$ & Negative regulator of type I IFN pathway & [123] \\
\hline & Let-7c & Blimp1 & Regulates SOCS1 and IL-6 & [139] \\
\hline \multirow{9}{*}{ B cells } & miR-30a & Lyn & Contributes to $\mathrm{B}$ cell proliferation and the production of IgG antibodies & [167] \\
\hline & $\operatorname{miR}-155$ & Pu.1 & Decreases the level of TNF alpha production & [110] \\
\hline & $\operatorname{miR}-181 b$ & AID & Less CSR in activated B cells & [173] \\
\hline & $\operatorname{miR}-150$ & c-Myb & Involved in lymphocyte development and response & {$[180]$} \\
\hline & miR-34a & Foxp1 & Involved in the regulation of B cell development & [181] \\
\hline & $\operatorname{miR}-125 b$ & Blimp-1, Irf4 & Contributes to B lymphocyte diversification in GC & [182] \\
\hline & miR-93 & AID & Less class switch recombination in activated B cells & [173] \\
\hline & $\operatorname{miR}-21$ & PDCD4 & Decreased the Fas receptor-expressing B cells & [166] \\
\hline & miR-1246 & EBF1 & Increase of miR-1246 expression results in less responsiveness of B cells & [170] \\
\hline \multirow{14}{*}{ T Cell } & miR-126 & DNMT1 & $\mathrm{T}$ and $\mathrm{B}$ cell hyperactivity, regulates DNA methylation in CD4+ T cells & [140] \\
\hline & miR-29b & DNMT1, Sp1 & More CD11a and CD70, unusually high global DNA hypomethylation in T cells & [143] \\
\hline & miR-148a & DNMT1 & More LFA1 and CD70, increase DNA hypomethylation in T cells & [141] \\
\hline & $\operatorname{miR}-21$ & RASGRP1 & Activated $\mathrm{T}$ cell and enhanced proliferation & [141] \\
\hline & miR-142-3p & CD84, IL-10 & Increased $\mathrm{T}$ cell activity and higher IgG production & [145] \\
\hline & miR-142-5p & SAP & Increased $\mathrm{T}$ cell activity and higher IgG production & [145] \\
\hline & $\operatorname{miR}-31$ & RhoA & More production of IL-12 by changing NF-AT expression & [148] \\
\hline & $\operatorname{miR}-125 \mathrm{a}$ & $\begin{array}{l}\text { KLF13 } \\
(\text { RFLAT-1) }\end{array}$ & $\begin{array}{c}\text { Negative regulator of the feedback loop of KLF13 and RANTES production in the activated } \\
\text { T cell pathway }\end{array}$ & [149] \\
\hline & miR-224 & AIP5 & Speeds activation-induced cell death in T cells & {$[93]$} \\
\hline & $\operatorname{miR}-155$ & CD62L & Important for Treg cell development and function & [100] \\
\hline & $\operatorname{miR}-873$ & Foxo1 & Eases differentiation of CD4+ T cells into Th17 lineage & [152] \\
\hline & $\operatorname{miR}-410$ & IL-6 & Lower IL-6 expression, less fibrosis & [157] \\
\hline & miR-125a & $\begin{array}{l}\text { STAT3, IL-13, } \\
\quad \text { IFNg }\end{array}$ & Steadies the commitment and immunoregulatory capacity of Treg cells & [160] \\
\hline & miR-181a & $\begin{array}{l}\text { SHP-2, PTPN22, } \\
\text { DUSP5, DUSP6 }\end{array}$ & Functions as an intrinsic antigen sensitivity "rheostat" throughout T cell development & [183] \\
\hline
\end{tabular}

validated 45 novel microRNAs expressed in developing B cells. Other previously mentioned study that investigated $\mathrm{T}$ and B cell populations in SLE showed seven microRNAs with differential expression in peripheral B cells in patients with SLE, compared to healthy controls [90]. These microRNAs include miR-150, miR-16, miR-15a, miR-155, miR-25, miR21 , and miR-106b. Notably, miR-21 is also overexpressed in splenic B cells from two mouse lupus models [141, 166]. Several studies described function of particular microRNAs in lupus B cells and some of the described microRNAs were associated with regulation of SLE susceptibility genes. For instance, an increase of miR-30a expression and its binding to the $3^{\prime}$-UTR of Lyn mRNA affected the phenotype of B cells in SLE patients [167]. Lyn, which was previously described as a crucial negative regulator of $\mathrm{B}$ cell activation, proliferation, and antibody production, is downregulated in B cells isolated from SLE patients [168, 169]. A similar function was described for miR-1246. The authors described that the expression of miR-1246 was significantly decreased in B cells from SLE patients. miR-1246 specifically targeted the EBF1 3 '-UTR region of mRNA and regulated the expression of EBF1 and consequently enhanced B cell function by increasing the number of $B$ cell surface costimulatory molecules CD40, CD80, and CD86 [170]. Other miRs expressed in B cells such as miR-155 and miR-181b downregulate the activation-induced cytidine deaminase (AID) [171-173] which plays important role in the regulation of $B$ cell activity. Nevertheless, the exact mechanism how miR-155 and miR$181 \mathrm{~b}$ regulate the function of AID remains unclear. Changes in miR-15a expression level were linked to its role in balancing different $B$ cell subsets such as immunosuppressive B-10 cells, conventional B-2 cells, and regulatory B-1 cell signaling and autoantibody production [174]. A study of Duroux-Richard et al. identified a miRNA signature of purified B cell subsets from renal and nonrenal severe SLE patients. Further statistical analysis of the miRNAs that were differentially expressed between all groups revealed that only a small number of miRNAs are significantly deregulated in 
the context of SLE [175]. This argument is supported by the transcriptional study of CD19+ B cells that reports weak differences between SLE patients and controls and pointing out the similarities at the transcriptomic level between normal and lupus B cells [176]. The differences between patients and controls appear quite weak with only 14 genes out of 18271 that appear to be differentially expressed (PMEPA1, TLR10, TRAF3IP2, LDOC1L, CD1C, and EGR1) [176]. Recently, cyclinD3 (CCND3) was suggested to play an important role in B cell proliferation, development, and differentiation. The activation of TLR7 increased CCND3 expression via the downregulation of miR-15b in B cells [177].

\section{Conclusions}

Tremendous efforts have been made to explore the crucial mechanisms responsible for the initiation and development of the autoimmunity. Although significant progress has taken place, there is still a strong need for reliable biomarkers for diagnosis and monitoring of the disease. Moreover, novel, efficient, and safe therapies need to be developed. Understanding of the role of microRNAs in the regulation of abnormal and imbalanced activation of immune responses may represent the new possibilities for development of better monitoring and therapies.

\section{Conflicts of Interest}

The authors declare that there is no conflict of interest regarding the publication of this paper.

\section{Acknowledgments}

The authors thank Dr. Werner Jackstädt-Stiftung for the support.

\section{References}

[1] G. C. Tsokos, "Systemic lupus erythematosus," The New England Journal of Medicine, vol. 365, no. 22, pp. 21102121, 2011.

[2] G. H. Ring and F. G. Lakkis, "Breakdown of self-tolerance and the pathogenesis of autoimmunity," Seminars in Nephrology, vol. 19, no. 1, pp. 25-33, 1999.

[3] P. Matzinger, "Tolerance, danger, and the extended family," Annual Review of Immunology, vol. 12, no. 1, pp. 991-1045, 1994.

[4] G. C. Tsokos and G. M. Kammer, "Molecular aberrations in human systemic lupus erythematosus," Trends in Molecular Medicine, vol. 6, no. 11, pp. 418-424, 2000.

[5] A. Kaul, C. Gordon, M. K. Crow et al., "Systemic lupus erythematosus," Nature Reviews Disease Primers, vol. 2, article 16039, 2016.

[6] C. Jiang, J. Foley, N. Clayton et al., "Abrogation of lupus nephritis in activation-induced deaminase-deficient MRL/ lpr mice," The Journal of Immunology, vol. 178, no. 11, pp. 7422-7431, 2007.
[7] P. E. Lipsky, "Systemic lupus erythematosus: an autoimmune disease of B cell hyperactivity," Nature Immunology, vol. 2, no. 9, pp. 764-766, 2001.

[8] G. C. Tsokos, M. S. Lo, P. Costa Reis, and K. E. Sullivan, "New insights into the immunopathogenesis of systemic lupus erythematosus," Nature Reviews Rheumatology, vol. 12, no. 12, pp. 716-730, 2016.

[9] M. Takeno, H. Nagafuchi, S. Kaneko et al., "Autoreactive $\mathrm{T}$ cell clones from patients with systemic lupus erythematosus support polyclonal autoantibody production," The Journal of Immunology, vol. 158, no. 7, pp. 35293538, 1997.

[10] J. C. Crispin, M. Oukka, G. Bayliss et al., "Expanded double negative T cells in patients with systemic lupus erythematosus produce IL-17 and infiltrate the kidneys," The Journal of Immunology, vol. 181, no. 12, pp. 8761-8766, 2008.

[11] D. Eilat and M. Wabl, "B cell tolerance and positive selection in lupus," The Journal of Immunology, vol. 189, no. 2, pp. 503-509, 2012.

[12] I. L. Dzhagalov, K. G. Chen, P. Herzmark, and E. A. Robey, "Elimination of self-reactive T cells in the thymus: a timeline for negative selection," PLoS Biology, vol. 11, no. 5, article e1001566, 2013

[13] N. V. Giltiay, C. P. Chappell, and E. A. Clark, "B-cell selection and the development of autoantibodies," Arthritis Research \& Therapy, vol. 14, article S1, Supplement 4, 2012.

[14] E. Meffre and H. Wardemann, "B-cell tolerance checkpoints in health and autoimmunity," Current Opinion in Immunology, vol. 20, no. 6, pp. 632-638, 2008.

[15] J. M. Kahlenberg, S. G. Thacker, C. C. Berthier, C. D. Cohen, M. Kretzler, and M. J. Kaplan, "Inflammasome activation of IL-18 results in endothelial progenitor cell dysfunction in systemic lupus erythematosus," The Journal of Immunology, vol. 187, no. 11, pp. 6143-6156, 2011.

[16] M. Aringer, C. Gunther, and M. A. Lee-Kirsch, "Innate immune processes in lupus erythematosus," Clinical Immunology, vol. 147, no. 3, pp. 216-222, 2013.

[17] J. M. Kahlenberg and M. J. Kaplan, "The inflammasome and lupus: another innate immune mechanism contributing to disease pathogenesis?," Current Opinion in Rheumatology, vol. 26, no. 5, pp. 475-481, 2014.

[18] M. Menon, P. A. Blair, D. A. Isenberg, and C. Mauri, "A regulatory feedback between plasmacytoid dendritic cells and regulatory B cells is aberrant in systemic lupus erythematosus," Immunity, vol. 44, no. 3, pp. 683-697, 2016.

[19] Z. Szondy, É. Garabuczi, G. Joos, G. J. Tsay, and Z. Sarang, "Impaired clearance of apoptotic cells in chronic inflammatory diseases: therapeutic implications," Frontiers in Immunology, vol. 5, p. 354, 2014.

[20] S. Nagata, R. Hanayama, and K. Kawane, "Autoimmunity and the clearance of dead cells," Cell, vol. 140, no. 5, pp. 619-630, 2010.

[21] N. Mozaffarian, A. E. Wiedeman, and A. M. Stevens, "Active systemic lupus erythematosus is associated with failure of antigen-presenting cells to express programmed death ligand-1," Rheumatology, vol. 47, no. 9, pp. 13351341, 2008.

[22] J. Zhu, X. Liu, C. Xie et al., "T cell hyperactivity in lupus as a consequence of hyperstimulatory antigen-presenting cells," The Journal of Clinical Investigation, vol. 115, no. 7, pp. 1869-1878, 2005. 
[23] O. T. Chan, L. G. Hannum, A. M. Haberman, M. P. Madaio, and M. J. Shlomchik, "A novel mouse with B cells but lacking serum antibody reveals an antibody-independent role for B cells in murine lupus," Journal of Experimental Medicine, vol. 189, no. 10, pp. 1639-1648, 1999.

[24] I. Sanz, "Rationale for B cell targeting in SLE," Seminars in Immunopathology, vol. 36, no. 3, pp. 365-375, 2014.

[25] A. Sang, Y. Y. Zheng, and L. Morel, "Contributions of B cells to lupus pathogenesis," Molecular Immunology, vol. 62, no. 2, pp. 329-338, 2014.

[26] Z. Liu and A. Davidson, "BAFF and selection of autoreactive B cells," Trends in Immunology, vol. 32, no. 8, pp. 388-394, 2011.

[27] M. Gayed and C. Gordon, "Novel treatments for systemic lupus erythematosus," Current Opinion in Investigational Drugs, vol. 11, no. 11, pp. 1256-1264, 2010.

[28] E. J. Lewis, L. G. Hunsicker, S. P. Lan, R. D. Rohde, J. M. Lachin, and for the lupus nephritis collaborative study group, "A controlled trial of plasmapheresis therapy in severe lupus nephritis," The New England Journal of Medicine, vol. 326, no. 21, pp. 1373-1379, 1992.

[29] R. J. Looney, J. H. Anolik, D. Campbell et al., "B cell depletion as a novel treatment for systemic lupus erythematosus: a phase I/II dose-escalation trial of rituximab," Arthritis \& Rheumatology, vol. 50, no. 8, pp. 2580-2589, 2004.

[30] V. R. Moulton and G. C. Tsokos, "Abnormalities of T cell signaling in systemic lupus erythematosus," Arthritis Research \& Therapy, vol. 13, no. 2, p. 207, 2011.

[31] J. C. Crispin, V. C. Kyttaris, Y. T. Juang, and G. C. Tsokos, "How signaling and gene transcription aberrations dictate the systemic lupus erythematosus T cell phenotype," Trends in Immunology, vol. 29, no. 3, pp. 110-115, 2008.

[32] P. Sawla, A. Hossain, B. H. Hahn, and R. P. Singh, "Regulatory $\mathrm{T}$ cells in systemic lupus erythematosus (SLE); role of peptide tolerance," Autoimmunity Reviews, vol. 11, no. 9, pp. 611-614, 2012.

[33] R. K. Dinesh, B. J. Skaggs, A. La Cava, B. H. Hahn, and R. P. Singh, "CD8 ${ }^{+}$Tregs in lupus, autoimmunity, and beyond," Autoimmunity Reviews, vol. 9, no. 8, pp. 560568, 2010.

[34] A. La Cava, "T-regulatory cells in systemic lupus erythematosus," Lupus, vol. 17, no. 5, pp. 421-425, 2008.

[35] P. P. Sfikakis, V. L. Souliotis, K. G. Fragiadaki, H. M. Moutsopoulos, J. N. Boletis, and A. N. Theofilopoulos, "Increased expression of the FoxP3 functional marker of regulatory $\mathrm{T}$ cells following $\mathrm{B}$ cell depletion with rituximab in patients with lupus nephritis," Clinical Immunology, vol. 123, no. 1, pp. 66-73, 2007.

[36] M. Vigna-Perez, B. Hernandez-Castro, O. Paredes-Saharopulos et al., "Clinical and immunological effects of rituximab in patients with lupus nephritis refractory to conventional therapy: a pilot study," Arthritis Research \& Therapy, vol. 8, no. 3, article R83, 2006.

[37] A. M. Cepika, I. Marinic, J. Morovic-Vergles, D. Soldo-Juresa, and A. Gagro, "Effect of steroids on the frequency of regulatory $\mathrm{T}$ cells and expression of FOXP3 in a patient with systemic lupus erythematosus: a two-year follow-up," Lupus, vol. 16, no. 5, pp. 374-377, 2007.

[38] W. N. Huang, T. K. Tso, H. C. Wu, H. F. Yang, and G. J. Tsay, "Impaired phagocytosis of apoptotic cell material in serologically active clinically quiescent patients with systemic lupus erythematosis," International Journal of Rheumatic Diseases, vol. 19, no. 12, pp. 1310-1316, 2016.

[39] J. Banchereau and R. M. Steinman, "Dendritic cells and the control of immunity," Nature, vol. 392, no. 6673, pp. 245252,1998 .

[40] J. Orme and C. Mohan, "Macrophage subpopulations in systemic lupus erythematosus," Discovery Medicine, vol. 13, no. 69, pp. 151-158, 2012.

[41] C. Ohnmacht, A. Pullner, S. B. King et al., "Constitutive ablation of dendritic cells breaks self-tolerance of CD4 T cells and results in spontaneous fatal autoimmunity," Journal of Experimental Medicine, vol. 206, no. 3, pp. 549$559,2009$.

[42] J. Dalgaard, K. J. Beckstrom, F. L. Jahnsen, and J. E. Brinchmann, "Differential capability for phagocytosis of apoptotic and necrotic leukemia cells by human peripheral blood dendritic cell subsets," Journal of Leukocyte Biology, vol. 77, no. 5, pp. 689-698, 2005.

[43] A. Iwasaki and R. Medzhitov, "Toll-like receptor control of the adaptive immune responses," Nature Immunology, vol. 5, no. 10, pp. 987-995, 2004.

[44] J. Klarquist, Z. Zhou, N. Shen, and E. M. Janssen, "Dendritic cells in systemic lupus erythematosus: from pathogenic players to therapeutic tools," Mediators of Inflammation, vol. 2016, Article ID 5045248, 12 pages, 2016.

[45] Y. Ito, H. Aoki, Y. Kimura, M. Takano, K. Shimokata, and K. Maeno, "Natural interferon-producing cells in mice," Infection and Immunity, vol. 31, no. 2, pp. 519523, 1981.

[46] A. N. Theofilopoulos, R. Baccala, B. Beutler, and D. H. Kono, "Type I interferons $(\alpha / \beta)$ in immunity and autoimmunity," Annual Review of Immunology, vol. 23, no. 1, pp. 307-335, 2005.

[47] G. Li, H. Zan, Z. Xu, and P. Casali, "Epigenetics of the antibody response," Trends in Immunology, vol. 34, no. 9, pp. 460-470, 2013.

[48] Y. Lee, K. Jeon, J. T. Lee, S. Kim, and V. N. Kim, "MicroRNA maturation: stepwise processing and subcellular localization," The EMBO Journal, vol. 21, no. 17, pp. 46634670, 2002.

[49] Y. Lee, C. Ahn, J. Han et al., "The nuclear RNase III Drosha initiates microRNA processing," Nature, vol. 425, no. 6956, pp. 415-419, 2003.

[50] M. Ha and V. N. Kim, "Regulation of microRNA biogenesis," Nature Reviews Molecular Cell Biology, vol. 15, no. 8, pp. 509524, 2014.

[51] A. Shiohama, T. Sasaki, S. Noda, S. Minoshima, and N. Shimizu, "Molecular cloning and expression analysis of a novel gene DGCR8 located in the DiGeorge syndrome chromosomal region," Biochemical and Biophysical Research Communications, vol. 304, no. 1, pp. 184-190, 2003.

[52] T. A. Nguyen, M. H. Jo, Y. G. Choi et al., "Functional anatomy of the human microprocessor," Cell, vol. 161, no. 6, pp. 1374-1387, 2015.

[53] A. M. Denli, B. B. Tops, R. H. Plasterk, R. F. Ketting, and G. J. Hannon, "Processing of primary microRNAs by the microprocessor complex," Nature, vol. 432, no. 7014, pp. 231-235, 2004.

[54] M. T. Bohnsack, K. Czaplinski, and D. Gorlich, "Exportin 5 is a RanGTP-dependent dsRNA-binding protein that mediates 
nuclear export of pre-miRNAs," RNA, vol. 10, no. 2, pp. 185191, 2004.

[55] R. Yi, Y. Qin, I. G. Macara, and B. R. Cullen, "Exportin-5 mediates the nuclear export of pre-microRNAs and short hairpin RNAs," Genes \& Development, vol. 17, no. 24, pp. 3011-3016, 2003.

[56] E. Lund, S. Guttinger, A. Calado, J. E. Dahlberg, and U. Kutay, "Nuclear export of microRNA precursors," Science, vol. 303, no. 5654, pp. 95-98, 2004.

[57] E. Bernstein, A. A. Caudy, S. M. Hammond, and G. J. Hannon, "Role for a bidentate ribonuclease in the initiation step of RNA interference," Nature, vol. 409, no. 6818, pp. 363-366, 2001.

[58] S. W. Knight and B. L. Bass, "A role for the RNase III enzyme DCR-1 in RNA interference and germ line development in Caenorhabditis elegans," Science, vol. 293, no. 5538, pp. 2269-2271, 2001.

[59] S. M. Hammond, S. Boettcher, A. A. Caudy, R. Kobayashi, and G. J. Hannon, "Argonaute2, a link between genetic and biochemical analyses of RNAi," Science, vol. 293, no. 5532, pp. 1146-1150, 2001.

[60] H. Tabara, M. Sarkissian, W. G. Kelly et al., "The $r d e-1$ gene, RNA interference, and transposon silencing in C. elegans," Cell, vol. 99, no. 2, pp. 123-132, 1999.

[61] T. Kawamata and Y. Tomari, "Making RISC," Trends in Biochemical Sciences, vol. 35, no. 7, pp. 368-376, 2010.

[62] T. Sasaki, A. Shiohama, S. Minoshima, and N. Shimizu, "Identification of eight members of the Argonaute family in the human genome," Genomics, vol. 82, no. 3, pp. 323-330, 2003.

[63] G. Meister, M. Landthaler, A. Patkaniowska, Y. Dorsett, G. Teng, and T. Tuschl, "Human Argonaute2 mediates RNA cleavage targeted by miRNAs and siRNAs," Molecular Cell, vol. 15, no. 2, pp. 185-197, 2004.

[64] J. Liu, M. A. Carmell, F. V. Rivas et al., "Argonaute2 is the catalytic engine of mammalian RNAi," Science, vol. 305, no. 5689, pp. 1437-1441, 2004.

[65] B. Berkhout and K. T. Jeang, "RISCy business: microRNAs, pathogenesis, and viruses," Journal of Biological Chemistry, vol. 282, no. 37, pp. 26641-26645, 2007.

[66] H. W. Hwang, E. A. Wentzel, and J. T. Mendell, "A hexanucleotide element directs microRNA nuclear import," Science, vol. 315, no. 5808, pp. 97-100, 2007.

[67] W. Filipowicz, S. N. Bhattacharyya, and N. Sonenberg, "Mechanisms of post-transcriptional regulation by microRNAs: are the answers in sight?," Nature Reviews Genetics, vol. 9, no. 2, pp. 102-114, 2008.

[68] J. S. Yang and E. C. Lai, “Alternative miRNA biogenesis pathways and the interpretation of core miRNA pathway mutants," Molecular Cell, vol. 43, no. 6, pp. 892-903, 2011.

[69] M. Xie and J. A. Steitz, "Versatile microRNA biogenesis in animals and their viruses," RNA Biology, vol. 11, no. 6, pp. 673-681, 2014.

[70] J. E. Babiarz, J. G. Ruby, Y. Wang, D. P. Bartel, and R. Blelloch, "Mouse ES cells express endogenous shRNAs, siRNAs, and other microprocessor-independent, dicerdependent small RNAs," Genes \& Development, vol. 22, no. 20, pp. 2773-2785, 2008.

[71] M. M. Chong, G. Zhang, S. Cheloufi, T. A. Neubert, G. J. Hannon, and D. R. Littman, "Canonical and alternate functions of the microRNA biogenesis machinery," Genes \& Development, vol. 24, no. 17, pp. 1951-1960, 2010.

[72] E. Berezikov, W. J. Chung, J. Willis, E. Cuppen, and E. C. Lai, "Mammalian mirtron genes," Molecular Cell, vol. 28, no. 2, pp. 328-336, 2007.

[73] J. G. Ruby, C. H. Jan, and D. P. Bartel, "Intronic microRNA precursors that bypass Drosha processing," Nature, vol. 448, no. 7149, pp. 83-86, 2007.

[74] C. Ender, A. Krek, M. R. Friedlander et al., "A human snoRNA with microRNA-like functions," Molecular Cell, vol. 32, no. 4, pp. 519-528, 2008.

[75] D. Cazalla, M. Xie, and J. A. Steitz, "A primate herpesvirus uses the integrator complex to generate viral microRNAs," Molecular Cell, vol. 43, no. 6, pp. 982-992, 2011.

[76] Y. Dai, Y. S. Huang, M. Tang et al., "Microarray analysis of microRNA expression in peripheral blood cells of systemic lupus erythematosus patients," Lupus, vol. 16, no. 12, pp. 939-946, 2007.

[77] R. Dai, Y. Zhang, D. Khan et al., "Identification of a common lupus disease-associated microRNA expression pattern in three different murine models of lupus," PLoS One, vol. 5, no. 12, article e14302, 2010.

[78] R. A. Bhanji, T. Eystathioy, E. K. Chan, D. B. Bloch, and M. J. Fritzler, "Clinical and serological features of patients with autoantibodies to GW/P bodies," Clinical Immunology, vol. 125, no. 3, pp. 247-256, 2007.

[79] A. Jakymiw, K. Ikeda, M. J. Fritzler, W. H. Reeves, M. Satoh, and E. K. Chan, "Autoimmune targeting of key components of RNA interference," Arthritis Research \& Therapy, vol. 8, no. 4, article R87, 2006.

[80] W. Sui, F. Liu, J. Chen, M. Ou, and Y. Dai, "Microarray technology for analysis of microRNA expression in renal biopsies of lupus nephritis patients," Methods in Molecular Biology, vol. 1134, pp. 211-220, 2014.

[81] S. K. Chauhan, V. V. Singh, R. Rai, M. Rai, and G. Rai, "Differential microRNA profile and post-transcriptional regulation exist in systemic lupus erythematosus patients with distinct autoantibody specificities," Journal of Clinical Immunology, vol. 34, no. 4, pp. 491-503, 2014.

[82] G. Wang, L. S. Tam, E. K. Li et al., "Serum and urinary free microRNA level in patients with systemic lupus erythematosus," Lupus, vol. 20, no. 5, pp. 493-500, 2011.

[83] A. L. Carlsen, A. J. Schetter, C. T. Nielsen et al., "Circulating microRNA expression profiles associated with systemic lupus erythematosus," Arthritis \& Rheumatology, vol. 65, no. 5, pp. 1324-1334, 2013.

[84] N. Shen, D. Liang, Y. Tang, N. de Vries, and P. P. Tak, "MicroRNAs-novel regulators of systemic lupus erythematosus pathogenesis," Nature Reviews Rheumatology, vol. 8, no. 12, pp. 701-709, 2012.

[85] J.-Q. Chen, G. Papp, S. Póliska et al., "MicroRNA expression profiles identify disease-specific alterations in systemic lupus erythematosus and primary Sjögren's syndrome," PLoS One, vol. 12, no. 3, article e0174585, 2017.

[86] E. A. Frangou, G. K. Bertsias, and D. T. Boumpas, "Gene expression and regulation in systemic lupus erythematosus," European Journal of Clinical Investigation, vol. 43, no. 10, pp. 1084-1096, 2013.

[87] J. L. Te, I. M. Dozmorov, J. M. Guthridge et al., "Identification of unique microRNA signature associated with lupus nephritis," PLoS One, vol. 5, no. 5, article e10344, 2010. 
[88] Y. Dai, W. Sui, H. Lan, Q. Yan, H. Huang, and Y. Huang, "Comprehensive analysis of microRNA expression patterns in renal biopsies of lupus nephritis patients," Rheumatology International, vol. 29, no. 7, pp. 749-754, 2009.

[89] C. G. Vinuesa, R. J. Rigby, and D. Yu, "Logic and extent of miRNA-mediated control of autoimmune gene expression," International Reviews of Immunology, vol. 28, no. 3-4, pp. 112-138, 2009.

[90] E. Stagakis, G. Bertsias, P. Verginis et al., "Identification of novel microRNA signatures linked to human lupus disease activity and pathogenesis: miR-21 regulates aberrant $\mathrm{T}$ cell responses through regulation of PDCD4 expression," Annals of the Rheumatic Diseases, vol. 70, no. 8, pp. 1496-1506, 2011.

[91] H. Wu, J. R. Neilson, P. Kumar et al., "miRNA profiling of naïve, effector and memory CD8 T cells," PLoS One, vol. 2, no. 10, article e1020, 2007.

[92] X. Luo, L. Zhang, M. Li et al., "The role of miR-125b in T lymphocytes in the pathogenesis of systemic lupus erythematosus," Clinical and Experimental Rheumatology, vol. 31, no. 2, pp. 263-271, 2013.

[93] M. C. Lu, N. S. Lai, H. C. Chen et al., "Decreased microRNA(miR)-145 and increased miR-224 expression in T cells from patients with systemic lupus erythematosus involved in lupus immunopathogenesis," Clinical \& Experimental Immunology, vol. 171, no. 1, pp. 91-99, 2013.

[94] H. Wang, W. Peng, X. Ouyang, W. Li, and Y. Dai, "Circulating microRNAs as candidate biomarkers in patients with systemic lupus erythematosus," Translational Research, vol. 160, no. 3, pp. 198-206, 2012.

[95] S. A. Muljo, K. M. Ansel, C. Kanellopoulou, D. M. Livingston, A. Rao, and K. Rajewsky, "Aberrant T cell differentiation in the absence of Dicer," Journal of Experimental Medicine, vol. 202, no. 2, pp. 261-269, 2005.

[96] M. M. Chong, J. P. Rasmussen, A. Y. Rudensky, and D. R. Littman, "The RNAseIII enzyme Drosha is critical in T cells for preventing lethal inflammatory disease," Journal of Experimental Medicine, vol. 205, no. 9, pp. 2005-2017, 2008.

[97] B. S. Cobb, T. B. Nesterova, E. Thompson et al., "T cell lineage choice and differentiation in the absence of the RNase III enzyme Dicer," Journal of Experimental Medicine, vol. 201, no. 9, pp. 1367-1373, 2005.

[98] X. Zhou, L. T. Jeker, B. T. Fife et al., "Selective miRNA disruption in $\mathrm{T}$ reg cells leads to uncontrolled autoimmunity," Journal of Experimental Medicine, vol. 205, no. 9, pp. 1983-1991, 2008.

[99] A. Liston, L. F. Lu, D. O'Carroll, A. Tarakhovsky, and A. Y. Rudensky, "Dicer-dependent microRNA pathway safeguards regulatory T cell function," Journal of Experimental Medicine, vol. 205, no. 9, pp. 1993-2004, 2008.

[100] A. A. Divekar, S. Dubey, P. R. Gangalum, and R. R. Singh, "Dicer insufficiency and microRNA-155 overexpression in lupus regulatory $\mathrm{T}$ cells: an apparent paradox in the setting of an inflammatory milieu," The Journal of Immunology, vol. 186, no. 2, pp. 924-930, 2011.

[101] L. Belver, V. G. de Yebenes, and A. R. Ramiro, "MicroRNAs prevent the generation of autoreactive antibodies," Immunity, vol. 33, no. 5, pp. 713-722, 2010.

[102] A. Ademokun and M. Turner, "Regulation of B-cell differentiation by microRNAs and RNA-binding proteins,"
Biochemical Society Transactions, vol. 36, no. 6, pp. 11911193, 2008.

[103] S. B. Koralov, S. A. Muljo, G. R. Galler et al., "Dicer ablation affects antibody diversity and cell survival in the B lymphocyte lineage," Cell, vol. 132, no. 5, pp. 860-874, 2008.

[104] S. Xu, K. Guo, Q. Zeng, J. Huo, and K. P. Lam, “The RNase III enzyme Dicer is essential for germinal center B-cell formation," Blood, vol. 119, no. 3, pp. 767-776, 2012.

[105] C. P. Morgan and T. L. Bale, "Sex differences in microRNA regulation of gene expression: no smoke, just miRs," Biology of Sex Differences, vol. 3, no. 1, p. 22, 2012.

[106] T. R. Pak, Y. S. Rao, S. A. Prins, and N. N. Mott, "An emerging role for microRNAs in sexually dimorphic neurobiological systems," Pflügers Archiv - European Journal of Physiology, vol. 465, no. 5, pp. 655-667, 2013.

[107] R. Cervera, A. Doria, Z. Amoura et al., "Patterns of systemic lupus erythematosus expression in Europe," Autoimmunity Reviews, vol. 13, no. 6, pp. 621-629, 2014.

[108] C. Libert, L. Dejager, and I. Pinheiro, "The X chromosome in immune functions: when a chromosome makes the difference," Nature Reviews Immunology, vol. 10, no. 8, pp. 594604, 2010.

[109] E. N. Fish, "The X-files in immunity: sex-based differences predispose immune responses," Nature Reviews Immunology, vol. 8, no. 9, pp. 737-744, 2008.

[110] H. R. Aboelenein, M. T. Hamza, H. Marzouk et al., "Reduction of CD19 autoimmunity marker on B cells of paediatric SLE patients through repressing PU.1/TNF- $\alpha /$ BAFF axis pathway by miR-155," Growth Factors, vol. 35, no. 2-3, pp. 49-60, 2017.

[111] N. Mellios, M. Galdzicka, E. Ginns et al., "Gender-specific reduction of estrogen-sensitive small RNA, miR-30b, in subjects with schizophrenia," Schizophrenia Bulletin, vol. 38, no. 3, pp. 433-443, 2012.

[112] O. Paris, L. Ferraro, O. M. Grober et al., "Direct regulation of microRNA biogenesis and expression by estrogen receptor beta in hormone-responsive breast cancer," Oncogene, vol. 31, no. 38, pp. 4196-4206, 2012.

[113] R. Dai, R. A. Phillips, Y. Zhang, D. Khan, O. Crasta, and S. A. Ahmed, "Suppression of LPS-induced interferongamma and nitric oxide in splenic lymphocytes by select estrogen-regulated microRNAs: a novel mechanism of immune modulation," Blood, vol. 112, no. 12, pp. 45914597, 2008.

[114] R. Dai, S. McReynolds, T. Leroith, B. Heid, Z. Liang, and S. A. Ahmed, "Sex differences in the expression of lupusassociated miRNAs in splenocytes from lupus-prone NZB/W $\mathrm{W}_{\mathrm{F} 1}$ mice," Biology of Sex Differences, vol. 4, no. 1, p. 19, 2013.

[115] E. Kassi and P. Moutsatsou, "Estrogen receptor signaling and its relationship to cytokines in systemic lupus erythematosus," Journal of Biomedicine and Biotechnology, vol. 2010, article 317452, 14 pages, 2010.

[116] N. Kanda and K. Tamaki, "Estrogen enhances immunoglobulin production by human PBMCs," The Journal of Allergy and Clinical Immunology, vol. 103, no. 2, pp. 282288, 1999.

[117] J. Venkatesh, H. Yoshifuji, D. Kawabata et al., "Antigen is required for maturation and activation of pathogenic antiDNA antibodies and systemic inflammation," The Journal of Immunology, vol. 186, no. 9, pp. 5304-5312, 2011. 
[118] B. P. Balaton and C. J. Brown, "Escape artists of the X chromosome," Trends in Genetics, vol. 32, no. 6, pp. 348-359, 2016.

[119] L. Carrel and H. F. Willard, "X-inactivation profile reveals extensive variability in X-linked gene expression in females," Nature, vol. 434, no. 7031, pp. 400-404, 2005.

[120] N. Shen, Q. Fu, Y. Deng et al., "Sex-specific association of Xlinked Toll-like receptor 7 (TLR7) with male systemic lupus erythematosus," Proceedings of the National Academy of Sciences of the United States of America, vol. 107, no. 36, pp. 15838-15843, 2010.

[121] Q. Lu, A. Wu, L. Tesmer, D. Ray, N. Yousif, and B. Richardson, "Demethylation of CD4OLG on the inactive $\mathrm{X}$ in T cells from women with lupus," The Journal of Immunology, vol. 179, no. 9, pp. 6352-6358, 2007.

[122] S. Laffont, N. Rouquie, P. Azar et al., "X-chromosome complement and estrogen receptor signaling independently contribute to the enhanced TLR7-mediated IFN- $\alpha$ production of plasmacytoid dendritic cells from women," The Journal of Immunology, vol. 193, no. 11, pp. 5444-5452, 2014.

[123] Y. Tang, X. Luo, H. Cui et al., "MicroRNA-146A contributes to abnormal activation of the type I interferon pathway in human lupus by targeting the key signaling proteins," Arthritis \& Rheumatology, vol. 60, no. 4, pp. 1065-1075, 2009.

[124] J. Hou, P. Wang, L. Lin et al., "MicroRNA-146a feedback inhibits RIG-I-dependent type I IFN production in macrophages by targeting TRAF6, IRAK1, and IRAK2," The Journal of Immunology, vol. 183, no. 3, pp. 2150-2158, 2009.

[125] V. S. Chan, Y. J. Nie, N. Shen, S. Yan, M. Y. Mok, and C. S. Lau, "Distinct roles of myeloid and plasmacytoid dendritic cells in systemic lupus erythematosus," Autoimmunity Reviews, vol. 11, no. 12, pp. 890-897, 2012.

[126] J. J. Karrich, L. C. Jachimowski, M. Libouban et al., “MicroRNA-146a regulates survival and maturation of human plasmacytoid dendritic cells," Blood, vol. 122, no. 17, pp. 3001-3009, 2013.

[127] B. Qu, J. Cao, F. Zhang et al., "Type I interferon inhibition of microRNA-146a maturation through up-regulation of monocyte chemotactic protein-induced protein 1 in systemic lupus erythematosus," Arthritis \& Rhematology, vol. 67, no. 12, pp. 3209-3218, 2015.

[128] J. Liu, L. Zhu, G. L. Xie, J. F. Bao, and Q. Yu, "Let-7 miRNAs modulate the activation of NF- $\kappa$ B by targeting TNFAIP3 and are involved in the pathogenesis of lupus nephritis," PLoS One, vol. 10, no. 6, article e0121256, 2015.

[129] W. Wang, J. Gao, and F. Wang, "MiR-663a/MiR-423-5p are involved in the pathogenesis of lupus nephritis via modulating the activation of NF- $\kappa$ B by targeting TNIP2," American Journal of Translational Research, vol. 9, no. 8, pp. 37963803, 2017.

[130] B. Tang, B. Xiao, Z. Liu et al., "Identification of MyD88 as a novel target of miR-155, involved in negative regulation of Helicobacter pylori-induced inflammation," FEBS Letters, vol. 584, no. 8, pp. 1481-1486, 2010.

[131] M. Ceppi, P. M. Pereira, I. Dunand-Sauthier et al., "MicroRNA-155 modulates the interleukin-1 signaling pathway in activated human monocyte-derived dendritic cells," Proceedings of the National Academy of Sciences of the United States of America, vol. 106, no. 8, pp. 2735-2740, 2009.

[132] P. Wang, J. Hou, L. Lin et al., "Inducible microRNA-155 feedback promotes type I IFN signaling in antiviral innate immunity by targeting suppressor of cytokine signaling 1," The Journal of Immunology, vol. 185, no. 10, pp. 6226-6233, 2010.

[133] H. Zhou, X. Huang, H. Cui et al., "miR-155 and its star-form partner miR-155* cooperatively regulate type I interferon production by human plasmacytoid dendritic cells," Blood, vol. 116, no. 26, pp. 5885-5894, 2010.

[134] H. Leiss, W. Salzberger, B. Jacobs et al., "MicroRNA 155deficiency leads to decreased autoantibody levels and reduced severity of nephritis and pneumonitis in pristane-induced lupus," PLoS One, vol. 12, no. 7, article e0181015, 2017.

[135] S. Zhou, Y. Wang, Y. Meng et al., "In vivo therapeutic success of microRNA-155 antagomir in a mouse model of lupus alveolar hemorrhage," Arthritis \& Rhematology, vol. 68, no. 4, pp. 953-964, 2016.

[136] S. Smith, T. Fernando, P. W. Wu et al., "MicroRNA-302d targets IRF9 to regulate the IFN-induced gene expression in SLE," Journal of Autoimmunity, vol. 79, pp. 105-111, 2017.

[137] M. Rossato, A. J. Affandi, S. Thordardottir et al., "Association of microRNA-618 expression with altered frequency and activation of plasmacytoid dendritic cells in patients with systemic sclerosis," Arthritis \& Rhematology, vol. 69, no. 9, pp. 1891-1902, 2017.

[138] Y. Deng, J. Zhao, D. Sakurai et al., "MicroRNA-3148 modulates allelic expression of toll-like receptor 7 variant associated with systemic lupus erythematosus," PLoS Genetics, vol. 9, no. 2, article e1003336, 2013.

[139] S. J. Kim, P. K. Gregersen, and B. Diamond, "Regulation of dendritic cell activation by microRNA let-7c and BLIMP1," The Journal of Clinical Investigation, vol. 123, no. 2, pp. 823-833, 2013.

[140] S. Zhao, Y. Wang, Y. Liang et al., "MicroRNA-126 regulates DNA methylation in CD4+ T cells and contributes to systemic lupus erythematosus by targeting DNA methyltransferase 1," Arthritis \& Rheumatology, vol. 63, no. 5, pp. 1376-1386, 2011.

[141] W. Pan, S. Zhu, M. Yuan et al., "MicroRNA-21 and microRNA-148a contribute to DNA hypomethylation in lupus $\mathrm{CD}^{+} \mathrm{T}$ cells by directly and indirectly targeting DNA methyltransferase 1," The Journal of Immunology, vol. 184, no. 12, pp. 6773-6781, 2010.

[142] X. Zhu, J. Liang, F. Li, Y. Yang, L. Xiang, and J. Xu, “Analysis of associations between the patterns of global DNA hypomethylation and expression of DNA methyltransferase in patients with systemic lupus erythematosus," International Journal of Dermatology, vol. 50, no. 6, pp. 697-704, 2011.

[143] H. Qin, X. Zhu, J. Liang et al., "MicroRNA-29b contributes to DNA hypomethylation of CD4+ T cells in systemic lupus erythematosus by indirectly targeting DNA methyltransferase 1," Journal of Dermatological Science, vol. 69, no. 1, pp. 61-67, 2013.

[144] F. J. Sheedy, E. Palsson-McDermott, E. J. Hennessy et al., "Negative regulation of TLR4 via targeting of the proinflammatory tumor suppressor PDCD4 by the microRNA miR21," Nature Immunology, vol. 11, no. 2, pp. 141-147, 2010.

[145] S. Ding, Y. Liang, M. Zhao et al., "Decreased microRNA-142$3 \mathrm{p} / 5 \mathrm{p}$ expression causes CD4+ T cell activation and B cell hyperstimulation in systemic lupus erythematosus," Arthritis \& Rheumatology, vol. 64, no. 9, pp. 2953-2963, 2012.

[146] J. Alcocer-Varela and D. Alarcon-Segovia, "Decreased production of and response to interleukin-2 by cultured 
lymphocytes from patients with systemic lupus erythematosus," The Journal of Clinical Investigation, vol. 69, no. 6, pp. 1388-1392, 1982.

[147] O. Boyman and J. Sprent, "The role of interleukin-2 during homeostasis and activation of the immune system," Nature Reviews Immunology, vol. 12, no. 3, pp. 180-190, 2012.

[148] W. Fan, D. Liang, Y. Tang et al., "Identification of microRNA-31 as a novel regulator contributing to impaired interleukin-2 production in T cells from patients with systemic lupus erythematosus," Arthritis \& Rheumatology, vol. 64, no. 11, pp. 3715-3725, 2012.

[149] X. Zhao, Y. Tang, B. Qu et al., "MicroRNA-125a contributes to elevated inflammatory chemokine RANTES levels via targeting KLF13 in systemic lupus erythematosus," Arthritis \& Rheumatology, vol. 62, no. 11, pp. 3425-3435, 2010.

[150] E. Katsuyama, M. Yan, K. S. Watanabe et al., "Downregulation of miR-200a-3p, targeting CtBP2 complex, is involved in the hypoproduction of IL-2 in systemic lupus erythematosus-derived T cells," The Journal of Immunology, vol. 198, no. 11, pp. 4268-4276, 2017.

[151] S. Zhu, W. Pan, X. Song et al., "The microRNA miR-23b suppresses IL-17-associated autoimmune inflammation by targeting TAB2, TAB3 and IKK- $\alpha$," Nature Medicine, vol. 18, no. 7, pp. 1077-1086, 2012.

[152] L. Liu, Y. Liu, M. Yuan, L. Xu, and H. Sun, "Elevated expression of microRNA-873 facilitates Th17 differentiation by targeting forkhead box O1 (Foxo1) in the pathogenesis of systemic lupus erythematosus," Biochemical and Biophysical Research Communications, vol. 492, no. 3, pp. 453-460, 2017.

[153] Q. Wan, Z. Zhou, S. Ding, and J. He, “The miR-30a negatively regulates IL-17-mediated signal transduction by targeting Traf3ip2," Journal of Interferon \& Cytokine Research, vol. 35, no. 11, pp. 917-923, 2015.

[154] D. J. Min, M. L. Cho, C. S. Cho et al., "Decreased production of interleukin-12 and interferon-? is associated with renal involvement in systemic lupus erythematosus," Scandinavian Journal of Rheumatology, vol. 30, no. 3, pp. 159-163, 2001.

[155] G. Grondal, I. Gunnarsson, J. Ronnelid, S. Rogberg, L. Klareskog, and I. Lundberg, "Cytokine production, serum levels and disease activity in systemic lupus erythematosus," Clinical and Experimental Rheumatology, vol. 18, no. 5, pp. 565-570, 2000.

[156] D. Liu, N. Zhang, X. Zhang, M. Qin, Y. Dong, and L. Jin, "MiR-410 down-regulates the expression of Interleukin-10 by targeting STAT3 in the pathogenesis of systemic lupus erythematosus," Cellular Physiology and Biochemistry, vol. 39, no. 1, pp. 303-315, 2016.

[157] D. Liu, N. Zhang, J. Zhang, H. Zhao, and X. Wang, "miR-410 suppresses the expression of interleukin- 6 as well as renal fibrosis in the pathogenesis of lupus nephritis," Clinical and Experimental Pharmacology and Physiology, vol. 43, no. 6, pp. 616-625, 2016.

[158] J. Cheng, R. Wu, L. Long et al., "miRNA-451a targets IFN regulatory factor 8 for the progression of systemic lupus erythematosus," Inflammation, vol. 40, no. 2, pp. 676687, 2017.

[159] Y. Wang, J. Liang, H. Qin et al., "Elevated expression of miR$142-3 \mathrm{p}$ is related to the pro-inflammatory function of monocyte-derived dendritic cells in SLE," Arthritis Research \& Therapy, vol. 18, no. 1, p. 263, 2016.
[160] W. Pan, S. Zhu, D. Dai et al., "MiR-125a targets effector programs to stabilize Treg-mediated immune homeostasis," Nature Communications, vol. 6, no. 1, article 7096, 2015.

[161] F. Allantaz, D. T. Cheng, T. Bergauer et al., "Expression profiling of human immune cell subsets identifies miRNAmRNA regulatory relationships correlated with cell type specific expression," PLoS One, vol. 7, no. 1, article e29979, 2012.

[162] S. H. Ramkissoon, L. A. Mainwaring, Y. Ogasawara et al., "Hematopoietic-specific microRNA expression in human cells," Leukemia Research, vol. 30, no. 5, pp. 643-647, 2006.

[163] K. Basso, P. Sumazin, P. Morozov et al., "Identification of the human mature B cell miRNome," Immunity, vol. 30, no. 5, pp. 744-752, 2009.

[164] R. Malumbres, K. A. Sarosiek, E. Cubedo et al., "Differentiation stage-specific expression of microRNAs in B lymphocytes and diffuse large B-cell lymphomas," Blood, vol. 113, no. 16, pp. 3754-3764, 2009.

[165] D. C. Spierings, D. McGoldrick, A. M. Hamilton-Easton et al., "Ordered progression of stage-specific miRNA profiles in the mouse B2 B-cell lineage," Blood, vol. 117, no. 20, pp. 53405349, 2011.

[166] B. G. Garchow, O. Bartulos Encinas, Y. T. Leung et al., "Silencing of microRNA-21 in vivo ameliorates autoimmune splenomegaly in lupus mice," EMBO Molecular Medicine, vol. 3, no. 10, pp. 605-615, 2011.

[167] Y. Liu, J. Dong, R. Mu et al., "MicroRNA-30a promotes B cell hyperactivity in patients with systemic lupus erythematosus by direct interaction with Lyn," Arthritis \& Rheumatology, vol. 65, no. 6, pp. 1603-1611, 2013.

[168] S. N. Liossis, E. E. Solomou, M. A. Dimopoulos, P. Panayiotidis, M. M. Mavrikakis, and P. P. Sfikakis, "B-cell kinase lyn deficiency in patients with systemic lupus erythematosus," Journal of Investigative Medicine, vol. 49, no. 2, pp. 157-165, 2001.

[169] F. Flores-Borja, P. S. Kabouridis, E. C. Jury, D. A. Isenberg, and R. A. Mageed, "Decreased Lyn expression and translocation to lipid raft signaling domains in B lymphocytes from patients with systemic lupus erythematosus," Arthritis \& Rheumatology, vol. 52, no. 12, pp. 3955-3965, 2005.

[170] S. Luo, Y. Liu, G. Liang et al., "The role of microRNA-1246 in the regulation of $\mathrm{B}$ cell activation and the pathogenesis of systemic lupus erythematosus," Clinical Epigenetics, vol. 7, no. 1, p. 24, 2015.

[171] Y. Dorsett, K. M. McBride, M. Jankovic et al., "MicroRNA155 suppresses activation-induced cytidine deaminasemediated Myc-Igh translocation," Immunity, vol. 28, no. 5, pp. 630-638, 2008.

[172] G. Teng, P. Hakimpour, P. Landgraf et al., "MicroRNA-155 is a negative regulator of activation-induced cytidine deaminase," Immunity, vol. 28, no. 5, pp. 621-629, 2008.

[173] V. G. de Yebenes, L. Belver, D. G. Pisano et al., "miR-181b negatively regulates activation-induced cytidine deaminase in B cells," Journal of Experimental Medicine, vol. 205, no. 10, pp. 2199-2206, 2008.

[174] Y. Yuan, S. Kasar, C. Underbayev et al., "Role of microRNA$15 \mathrm{a}$ in autoantibody production in interferon-augmented murine model of lupus," Molecular Immunology, vol. 52, no. 2, pp. 61-70, 2012.

[175] I. Duroux-Richard, J. Cuenca, C. Ponsolles et al., "MicroRNA profiling of B cell subsets from systemic lupus erythematosus patients reveals promising novel biomarkers," International 
Journal of Molecular Sciences, vol. 16, no. 8, pp. 16953-16965, 2015.

[176] J. C. Garaud, J. N. Schickel, G. Blaison et al., "B cell signature during inactive systemic lupus is heterogeneous: toward a biological dissection of lupus," PLoS One, vol. 6, no. 8, article e23900, 2011.

[177] D. Ren, F. Liu, G. Dong et al., “Activation of TLR7 increases CCND3 expression via the downregulation of miR-15b in B cells of systemic lupus erythematosus," Cellular \& Molecular Immunology, vol. 13, no. 6, pp. 764-775, 2016.

[178] J. Agudo, A. Ruzo, N. Tung et al., "The miR-126-VEGFR2 axis controls the innate response to pathogen-associated nucleic acids," Nature Immunology, vol. 15, no. 1, pp. 5462, 2014.

[179] S. Yan, L. Y. Yim, R. C. Tam et al., "MicroRNA-155 mediates augmented CD40 expression in bone marrow derived plasmacytoid dendritic cells in symptomatic lupus-prone NZB/ W F1 mice," International Journal of Molecular Sciences, vol. 17, no. 8, article 1282, 2016.

[180] C. Xiao, D. P. Calado, G. Galler et al., "MiR-150 controls $\mathrm{B}$ cell differentiation by targeting the transcription factor c-Myb," Cell, vol. 131, no. 1, pp. 146-159, 2007.

[181] D. S. Rao, R. M. O'Connell, A. A. Chaudhuri, Y. Garcia-Flores, T. L. Geiger, and D. Baltimore, "MicroRNA-34a perturbs B lymphocyte development by repressing the forkhead box transcription factor Foxp1," Immunity, vol. 33, no. 1, pp. 4859, 2010.

[182] M. Gururajan, C. L. Haga, S. Das et al., "MicroRNA 125b inhibition of B cell differentiation in germinal centers," International Immunology, vol. 22, no. 7, pp. 583-592, 2010.

[183] Q. J. Li, J. Chau, P. J. Ebert et al., "miR-181a is an intrinsic modulator of T cell sensitivity and selection," Cell, vol. 129, no. 1, pp. 147-161, 2007. 


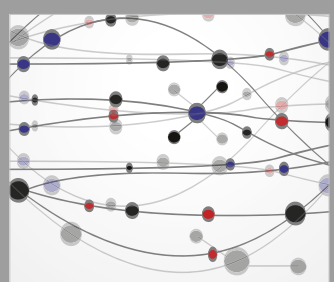

The Scientific World Journal
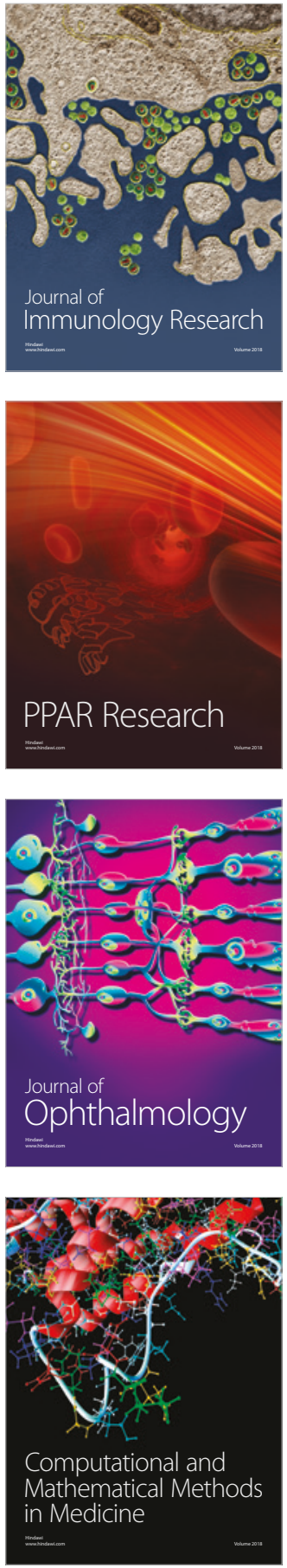

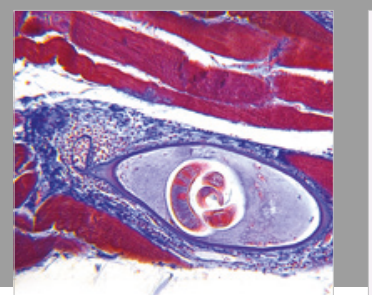

Gastroenterology Research and Practice

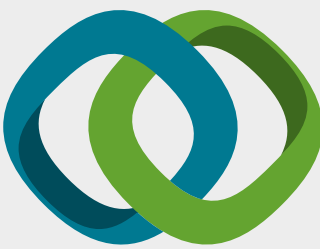

\section{Hindawi}

Submit your manuscripts at

www.hindawi.com
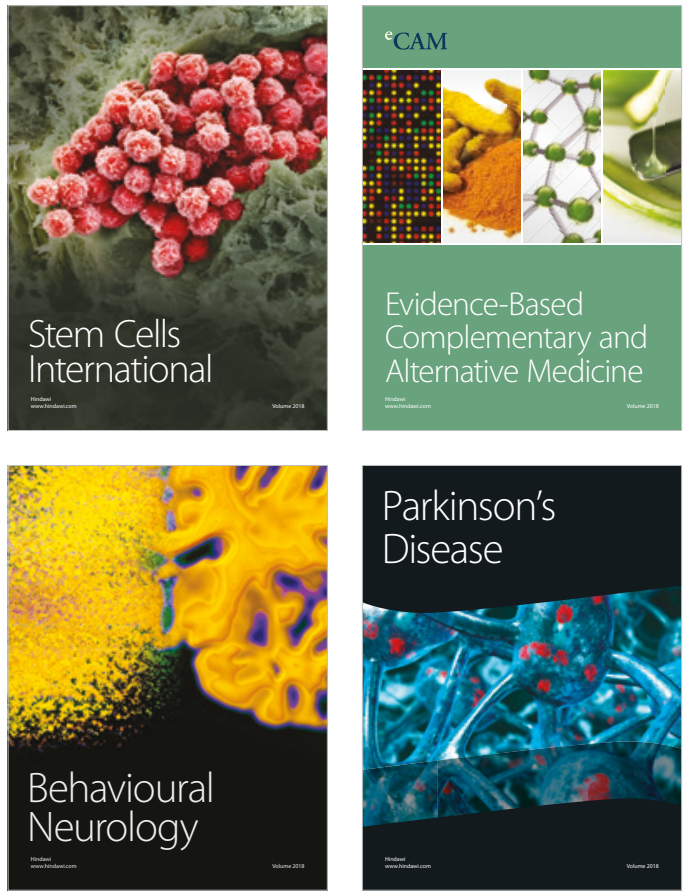

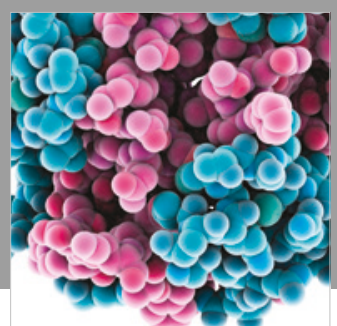

ournal of

Diabetes Research

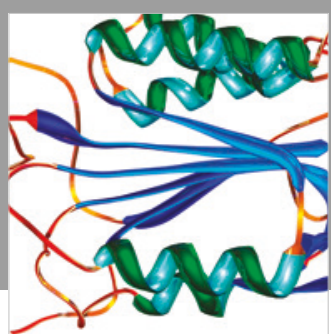

Disease Markers
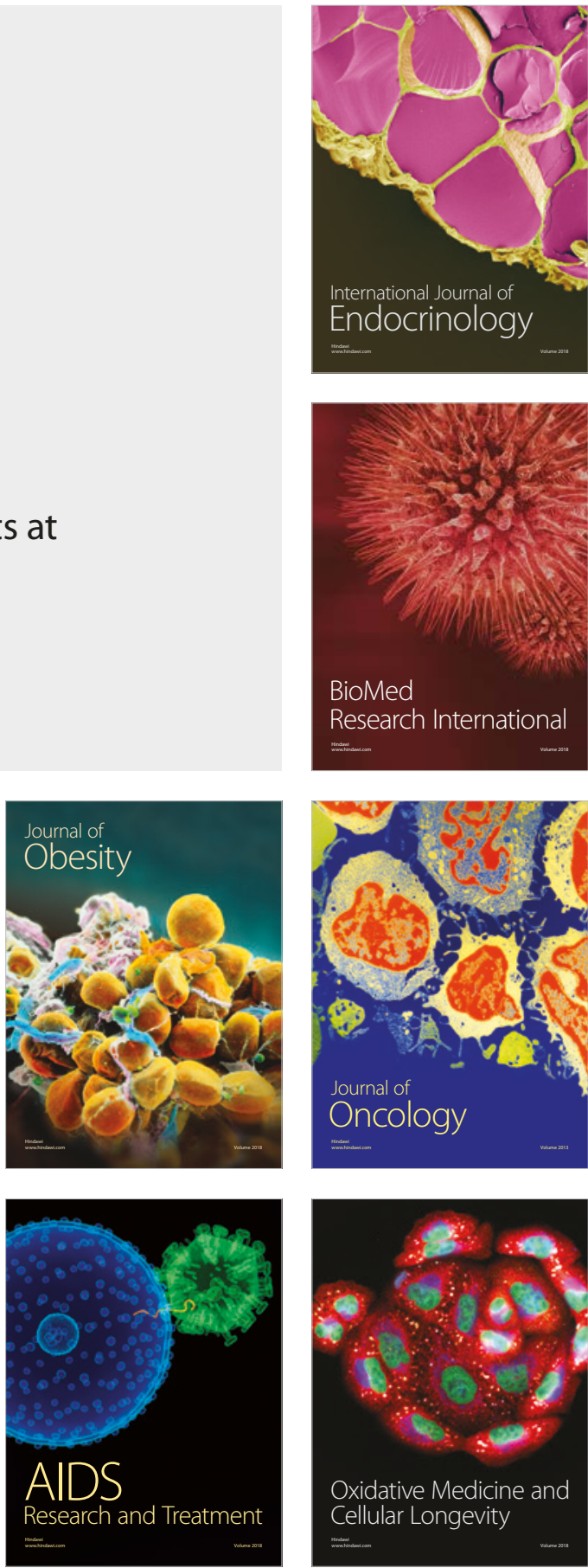